\title{
Relationship between hyperoxemia and ventilator associated pneumonia
}

\author{
Karim Jaffal $^{1}$, Sophie Six ${ }^{1,2}$, Farid Zerimech ${ }^{3}$, Saad Nseir ${ }^{1,2}$ \\ ${ }^{1}$ CHU Lille, Centre de Réanimation, Lille, France; ${ }^{2}$ Lille University, Faculté de Médecine, Lille, France; ${ }^{3}$ CHU Lille, Centre de Biologie et de \\ Pathologie, Lille, France \\ Contributions: (I) Conception and design: K Jaffal, S Six, S Nseir; (II) Administrative support: None; (III) Provision of study materials or patients: \\ None; (IV) Collection and assembly of data: K Jaffal, S Six; (V) Data analysis and interpretation: All authors; (VI) Manuscript writing: All authors; (VII) \\ Final approval of manuscript: All authors. \\ Correspondence to: Prof. Saad Nseir. CHU Lille, Centre de Réanimation, F-59000 Lille, France. Email: s-nseir@chru-lille.fr.
}

\begin{abstract}
Previous studies suggest a relationship between hyperoxemia and ventilator-associated pneumonia (VAP). Hyperoxemia is responsible for denitrogenation phenomena, and inhibition of surfactant production, promoting atelectasis in mechanically ventilated patients. Further, hyperoxemia impairs the efficacy of alveolar macrophages to migrate, phagocyte and kill bacteria. Oxygen can also cause pulmonaryspecific toxic effect called hyperoxic acute lung injury leading to longer duration of mechanical ventilation. All these hyperoxic effects are well-known risk factors for VAP. A recent retrospective large single center study identified hyperoxemia as an independent risk factor for VAP. However, two recent randomized controlled trials evaluated the impact of conservative oxygen strategy versus a liberal strategy, but did not confirm the role of hyperoxemia in lower respiratory tract infection occurrence. In this review, we discuss animal and human studies suggesting a relationship between these two common conditions in mechanically ventilated patients and potential interventions that should be evaluated. Further large prospective studies in carefully selected groups of patients are required to confirm the potential role of hyperoxemia in VAP pathogenesis and to evaluate the impact of a conservative oxygen strategy $v s$. a conventional strategy on the incidence of VAP.
\end{abstract}

Keywords: Hyperoxemia; ventilator-associated pneumonia (VAP); infection; intensive care unit (ICU)

Submitted Oct 03, 2017. Accepted for publication Oct 10, 2017.

doi: 10.21037/atm.2017.10.15

View this article at: http://dx.doi.org/10.21037/atm.2017.10.15

\section{Introduction}

High concentrations of oxygen are routinely used during the supportive care in critically ill patients $(1,2)$. Liberal oxygen therapy is supposed to prevent hypoxia and improve oxygen supply to the different affected organs. However, oxygen toxicity has recently raised concern regarding the liberal use of oxygen. Because of its unique properties as a final electron receptor, $\mathrm{O}_{2}$ allows high rate of adenosine triphosphate (ATP) synthesis in the respiratory chain pathway, making molecular $\mathrm{O}_{2}$ vital for mammalian cells. However, $\mathrm{O}_{2}$ is among the strongest oxidizing agents due to its high oxidizing chemical property that can damage all biological molecules $(3,4)$.

Hyperoxemia commonly occurs because clinicians maintain super-normal $\mathrm{PaO}_{2}$ to provide a buffer or margin of safety in case of acute desaturation, forgetting that the $\mathrm{O}_{2}$ carrying capacity of plasma is minor $(0.003 \mathrm{~mL} / \mathrm{dL} / \mathrm{mm} \mathrm{Hg}$ of $\left.\mathrm{PaO}_{2}\right)$, as compared with hemoglobin $(1.39 \mathrm{~mL} / \mathrm{g} / \mathrm{dL})$. The main end point should be tissue oxygenation that reflects the balance between oxygen delivery and tissue consumption. In most of cases hyperoxemia does not lead to adjustment of ventilator settings if inspired oxygen fraction $\left(\mathrm{FiO}_{2}\right)<0.40$, level generally considered safe by clinicians $(4,5)$.

Although existing data remain conflicting regarding the risk related to hyperoxemia in critical care, results from the 
latest clinical studies suggest that hyperoxemia is probably associated with worse outcomes in some critically ill patients $(6,7)$. Potential reasons for these conflicting results are significant heterogeneity between the studies regarding hyperoxemia definition, time of assessment, cutoffs, timing and duration of hyperoxemia. Two meta-analyses suggest that hyperoxemia is associated with increased mortality in different populations of critically ill patients $(8,9)$, including post-cardiac arrest $\left[\mathrm{OR}=1.42(1.04-1.92), \mathrm{I}^{2}=68 \%\right]$, stroke $\left[\mathrm{OR}=1.23(1.06-1.43), \mathrm{I}^{2}=0 \%\right]$, and traumatic brain injury [OR $=1.41(1.03-1.94), \mathrm{I}^{2}=65 \%$ ].

Previous studies suggested a relationship between hyperoxemia and ventilator-associated pneumonia (VAP). VAP is the most common intensive care unit (ICU)-acquired infection (10) and is associated with high mortality, duration of mechanical ventilation, and cost (11). Better understanding of pathophysiology and risk factors for VAP is a key issue in improving preventive strategies. The aim of this narrative review is to discuss animal and clinical studies regarding the possible relationship between hyperoxemia and VAP.

\section{Experimental studies}

Oxygen toxicity is mainly related to the formation of reactive oxygen species (ROS), especially during hypoxia/ re-oxygenation and long exposure to oxygen (12-14). The enhanced rate of ROS formation is directly related to the $\mathrm{O}_{2}$ partial pressure. ROS have both toxic and vital potential for host defense and as signaling molecules $(15,16)$.

It has been well-established for more than a century that pulmonary $\mathrm{O}_{2}$ toxicity may cause severe pulmonary inflammation leading to hemorrhagic pulmonary edema and fibrosis (17-20). High level of $\mathrm{FiO}_{2}$ is responsible for denitrogenation phenomena and inhibition of surfactant production promoting expiratory collapse and atelectasis (21-23). Adsorption atelectasis occurs within few minutes after pure $\mathrm{O}_{2}$ breathing (23-25). In mechanically ventilated patients, atelectasis seriously impairs cough reflex and mucus clearance resulting in abundant secretions in the lower airways and higher risk for $\operatorname{VAP}(26,27)$.

Prolonged hyperoxia impairs the efficacy of alveolar macrophages to migrate, phagocyte and kill bacteria (28-31), resulting in decreased bacterial clearance. Hyperoxemia markedly increased the lethality of both Legionella pneumophila and Pseudomonas aeruginosa in a mouse models of pneumonia $(32,33)$. No mortality was observed in mice exposed to either bacterial inoculation or hyperoxemia alone, but this combination lead to loss of barrier integrity and systemic dissemination of bacteria (32). This increased mortality in animals occurred even at $40 \%$ to $65 \%$ of $\mathrm{FiO}_{2}$ $(31,34,35)$, levels generally considered safe by clinicians (36).

Additionally, $\mathrm{O}_{2}$ can cause pulmonary-specific toxic effect called hyperemic acute lung injury (HALI) (13), initially described by Smith et al. in 1899 (37,38). Hyaline membrane formation, pulmonary arteriole thickening, and alteration in the ventilation/perfusion fraction are the main mechanisms described (13). The pathophysiology of HALI is similar to that of acute respiratory distress syndrome (ARDS).

All the above-discussed side effects of hyperoxemia, including pulmonary inflammation, atelectasis, and impaired bacteria clearance are well-known risk factors for VAP (39-43). The impact of these consequences of hyperoxemia on VAP occurrence is presented in Figure 1.

\section{Clinical studies}

Observational studies reported that hyperoxemia was present in more than $50 \%$ of mechanically ventilated patients during the first $24 \mathrm{~h}$ after ICU admission $(1,44)$. Although several observational studies suggested an association between hyperoxemia and poor hospital outcomes, recent meta-analyses were inconclusive due to the high data heterogeneity $(4,8)$. However, recent randomized controlled trials also suggest that hyperoxemia might be harmful in critically ill patients.

Girardis and colleagues performed a large randomized controlled trial to evaluate the impact of conservative $\left(\mathrm{PaO}_{2}\right.$ between 70 and $100 \mathrm{mmHg}$, or $\mathrm{SpO}_{2}$ between $94 \%$ and $98 \%)$ versus conventional oxygen therapy $\left(\mathrm{PaO}_{2}\right.$ values up to $150 \mathrm{mmHg}$, or $\mathrm{SpO}_{2}$ values between $97 \%$ and $100 \%$ ) on mortality in ICU patients (6). ICU-mortality rate was significantly lower in the conservative compared with the conventional group [11.6\% vs. $20.2 \%$, absolute risk reduction 0.086 (95\% CI: 0.017-0.150)]. Although the rate of new bloodstream infections was significantly lower in the conservative compared with the conventional group [absolute risk reduction 0.005 (95\% CI: 0.000-0.009)], the rate of nosocomial respiratory infections was similar in the two groups. However, several confounders could have influenced the results reported by Girardis and colleagues regarding the absence of significant impact of hyperoxemia on respiratory infection rate. First, the authors used CDC criteria to define respiratory infections. These criteria are not specific, and the authors did not clearly differentiate ventilator-associated tracheobronchitis (VAT) from VAP. Although these infections are classified as respiratory 


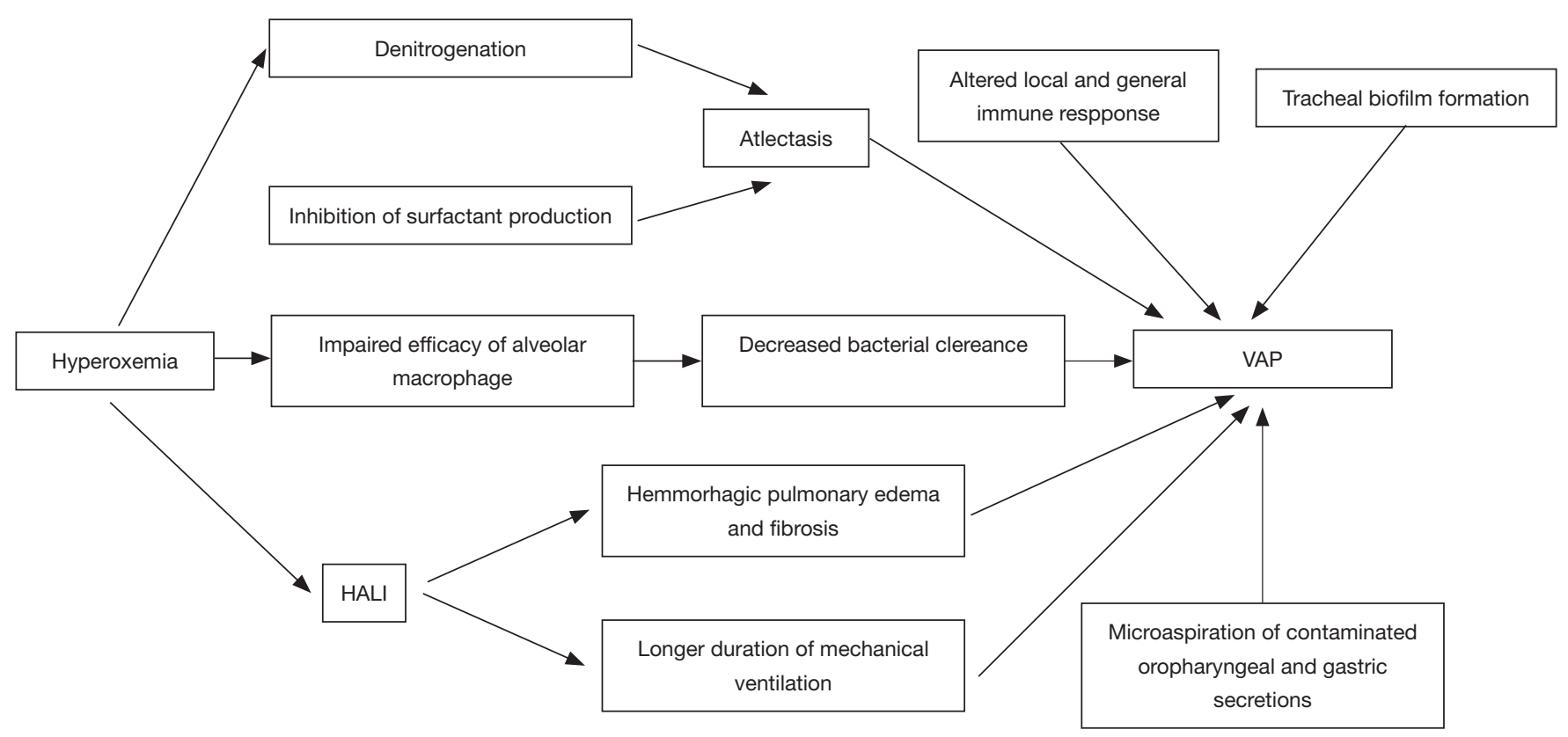

Figure 1 Relationship between hyperoxemia and VAP. VAP, ventilator-associated pneumonia; HALI, hyperoxic acute lung injury.

infections by CDC criteria, their impact on mortality is clearly different. A recent large observational multinational study showed that VAP, but not VAT, was associated with significantly higher mortality rate, compared with patients with no lower respiratory tract infections (45). Second, no information is given on the methods used to obtain the microbiological confirmation in patients with respiratory infections. It is well known that the use of quantitative methods substantially improves the specificity of VAP diagnosis. Third, the exclusion of immunosuppressed, ARDS, and COPD patients might have influenced their results, as these patients are at higher risk for VAP. Fourth, no information is give on incidence density of VAT and VAP (number of infections per 1,000 mechanical ventilation days) in study groups.

Recently, Asfar and colleagues performed a two-by-two factorial, randomized controlled clinical trial (HYPERS2S) to determine the impact of hyperoxemia and fluid resuscitation with hypertonic saline solution in patients with septic shock, versus normoxemia and isotonic saline on mortality (7). The trial was stopped early for safety reasons, and the authors concluded that in patients with septic shock setting $\mathrm{FiO}_{2}$ to 1.0 to induce hyperoxemia might increase the risk of mortality, and hypertonic saline did not improve survival. Interestingly, the percentage of patients with atelectasis doubled in patients with hyperoxemia compared with those with normoxemia (12\% vs. $6 \%, \mathrm{P}=0.04)$. However, no significant difference was found in nosocomial pneumonia rate between the two groups ( $15 \%$ vs. $14 \%, \mathrm{P}=0.78)$. ICU-acquired pneumonia was not the primary outcome of this trial. Moreover, several other factors preclude any valuable conclusion on the relationship between hyperoxemia and ICU-acquired pneumonia (46). First, no clear definition is given for ICUacquired pneumonia, and if the same definition of ICUacquired pneumonia was used in the different participating ICUs $(n=22)$ is not reported. Second, the density rate of ICU-acquired pneumonia is not provided. Third, whether quantitative microbiological confirmation was required in all patients is unknown. Although the incidence of ICUacquired pneumonia is in line with rates reported by French ICUs, applying different diagnostic criteria to the same patient population can result in wide variation in the incidence of nosocomial pneumonia. A recent study showed that the incidence of VAP ranged from $4 \%$ to $42 \%$ when using the six published sets of criteria in the same cohort of patients (47). Further, it is well known that the use of quantitative methods substantially improves the specificity of VAP diagnosis.

Rachmale and colleagues (48) prospectively evaluated the electronic medical record of 289 ICU patients with acute lung injury to assess excessive oxygen exposure and its effect 
on pulmonary outcomes. Excessive $\mathrm{FiO}_{2}$ was defined as $\mathrm{FiO}_{2}$ $>0.5$. Results showed that $74 \%$ of the included patients were exposed to hyperoxemia. A correlation between prolonged $\mathrm{FiO}_{2}$ exposure and worsening of oxygenation index in 48 hours, as well as an association between hyperoxemia and longer duration of mechanical ventilation and ICU stay were demonstrated (48). Another recent large multicenter cohort study found severe hyperoxemia to be associated with fewer ventilator-free days and higher mortality (4). Longer duration of mechanical ventilation is a well-known a factor risk for VAP (49).

Our group performed a large single center cohort study to determine the relationship between hyperoxemia and VAP (50). VAP was diagnosed using clinical, radiological and quantitative microbiological data in $28 \%$ (128 out of 503) of study patients. Multivariate analysis identified number of days spent with hyperoxemia $[\mathrm{OR}=1.1,95 \% \mathrm{CI}$ : (1.04-1.2) per day, $\mathrm{P}=0.004]$, simplified acute physiology score (SAPS) II [OR $=1.01,95 \%$ CI: $(1.002-1.024)$ per point, $\mathrm{P}<0.05]$, red blood cell transfusion $(\mathrm{OR}=1.8,95 \%$ CI: $1.2-2.7, \mathrm{P}=0.01$ ), and proton pomp inhibitor use (OR $=1.9,95 \%$ CI: $1.03-1.2, \mathrm{P}<0.05)$ as independent risk factors for VAP. Other multiple regression models also identified hyperoxemia at ICU admission (OR $=1.89,95 \%$ CI: $1.23-$ $2.89, \mathrm{P}=0.004)$, and percentage of days with hyperoxemia $(\mathrm{OR}=2.2,95 \% \mathrm{CI}: 1.08-4.48, \mathrm{P}=0.029)$ as independent risk factors for VAP. However, the study was retrospective, performed in a single center, and the definition used for hyperoxemia (at least one $\mathrm{PaO}_{2}$ value $>120 \mathrm{mmHg}$ per day) could be a matter for debate.

\section{Future research and potential interventions}

\section{Conservative $\mathrm{O}_{2}$ strategy}

The results of recent studies highlight the importance of clinical management strategies that prevent hypoxemia while minimizing the incidence of hyperoxemia (51). Even now, nearly 240 years after the discovery of $\mathrm{O}_{2}$, what constitutes the safe upper limits and duration of $\mathrm{FiO}_{2}$ remains uncertain. Toxicity rose more rapidly as $\mathrm{FiO}_{2}$ is increased above 0.6 and also as exposure time is prolonged $(4,18,37,38)$. Available data showed a U-shaped relationship between mortality and arterial $\mathrm{PaO}_{2}$ (52). Mortality sharply increased at $\mathrm{PaO}_{2}<65$ and $>225 \mathrm{mmHg}$ (1). Based on these concerns and the fact that optimizing oxygenation targets may improve patients' outcome, oxygen titration should be done. With appropriate safeguards, lower oxygenation targets may be acceptable and possibly beneficial in many critically ill patients.

Conservative oxygen therapy with careful oxygen titration is aimed at the prevention of iatrogenic hyperoxemia while preserving adequate tissue oxygenation. Several studies have now compared so-called conservative oxygen strategies targeting lower $\mathrm{PaO}_{2}$ or $\mathrm{SpO}_{2}$ values with conventional oxygen administration and reported no significant differences in terms of organ dysfunction or ICU and 90-day mortality $(6,8,9,53)$. Suzuki et al. reported a lower atelectasis score and shorter duration of mechanical ventilation in the conservative oxygen therapy group, as compared with the liberal group (54,55). Also, in the study of Helmerhorst et al., ventilator-free days were greater higher in the conservative oxygen therapy, as compared with liberal oxygen group $(4,56)$. Further, conservative oxygen strategy seems to be safe and feasible $(53,54,56)$.

\section{Permissive hypoxemia}

The conservative oxygen strategy has led to the concept of permissive hypoxemia (with hemoglobin concentration $9-10 \mathrm{~g} / \mathrm{dL}$ and normal cardiac index $4.7 \mathrm{~L} / \mathrm{min} / \mathrm{m}^{2}$, in order to maintain normal $\mathrm{O}_{2}$ tissue delivery) in some selected patients with a high risk of hyperoxemia like severe ARDS patients. This oxygen administration strategy works as a lung-protective strategy that aims to minimize the detrimental effects of the usual ventilatory support in the ICU (57). Although studies supported the feasibility of permissive hypoxemia, evidence is still lacking in terms of the efficacy $(53,58)$. Recently, the UK and Australian Benefits of Oxygen Saturation Targeting (BOOST) II trials showed an oxygen saturation target of $85 \%$ to $89 \%$, rather than $91 \%$ to $95 \%$, may increase the risk for death or disability at 2 years corrected age in infants born before age 28 weeks (59). No study in adults is yet available.

\section{Automated $\mathrm{FiO}_{2}$ adjustment}

With the use of pulse oximetry and computer technology, several attempts have been made to automate the adjustment of $\mathrm{FiO}_{2}$, especially in neonatology, because of the frequent and unpredictable change of oxygenation and risks of hyperoxemia in premature babies (60) as well as for titrating the $\mathrm{FiO}_{2}$ for COPD patients requiring long-term oxygen therapy (61). These systems proved a reduction in oxygen use without inducing hypoxemia compared with conventional adjustments. Last, a recent mode of ventilation 
allows full control of both pressure-targeted breaths and the level of $\mathrm{FiO}_{2}$ in a closed-loop manner (62-64).

\section{Antioxydants supplementation}

Antioxidant supplementation has been used to reduce hyperoxemia-compromised host defense by scavenging hyperoxemia-induced excessive intracellular ROS. Treatment of hyperoxemia-exposed macrophages with antioxidants, such as superoxide dismutase can preserve actin cytoskeleton organization and increase the phagocytosis of bacteria $(31,65)$. Hyperoxemia-exposed cells overexpressing antioxidant enzyme manganese superoxide dismutase, have increased phagocytic activity, attenuated ROS-induced damage and reduced bacterial adherence $(65,66)$. In a mice model exposed to hyperoxemia, ascorbic acid supplementation significantly improved bacterial clearance of $P$. aeruginosa (67). Another recent animal study suggests that hyperoxemia increases mortality in mice with Acinetobacter baumannii pneumonia, and that procysteine improves survival by increasing the phagocytic activity of alveolar macrophages (68). These findings suggest that supplementation with antioxidants during supportive oxygen therapy may be an effective intervention to attenuate or prevent the development of VAP in critically ill patients. A better understanding of the signaling pathways induced by hyperoxemia may provide valuable insights on its pathogenesis and may help in designing more effective therapeutic approaches.

\section{Conclusions}

Animal and clinical studies suggest a link between hyperoxemia and VAP. However, further large prospective studies in carefully selected groups of patients are required to confirm these findings and to evaluate the impact of a conservative oxygen strategy $v s$. a conventional strategy on the incidence of VAP.

\section{Acknowledgements}

None.

\section{Footnote}

Conflicts of Interest: S Nseir-Medtronic, and MSD (lecture); Ciel Medical, and Bayer (advisory board). The other authors have no conflicts of interest to declare.

\section{References}

1. de Jonge E, Peelen L, Keijzers PJ, et al. Association between administered oxygen, arterial partial oxygen pressure and mortality in mechanically ventilated intensive care unit patients. Crit Care 2008;12:R156.

2. Suzuki S, Eastwood GM, Peck L, et al. Current oxygen management in mechanically ventilated patients: a prospective observational cohort study. J Crit Care 2013;28:647-54.

3. Vincent JL, Taccone FS, He X. Harmful Effects of Hyperoxia in Postcardiac Arrest, Sepsis, Traumatic Brain Injury, or Stroke: The Importance of Individualized Oxygen Therapy in Critically Ill Patients. Can Respir J 2017;2017:2834956.

4. Helmerhorst HJ, Arts DL, Schultz MJ, et al. Metrics of Arterial Hyperoxia and Associated Outcomes in Critical Care. Crit Care Med 2017;45:187-95.

5. Hafner S, Beloncle F, Koch A, et al. Hyperoxia in intensive care, emergency, and peri-operative medicine: Dr. Jekyll or Mr. Hyde? A 2015 update. Ann Intensive Care 2015;5:42.

6. Girardis M, Busani S, Damiani E, et al. Effect of Conservative vs Conventional Oxygen Therapy on Mortality Among Patients in an Intensive Care Unit: The Oxygen-ICU Randomized Clinical Trial. JAMA 2016;316:1583-9.

7. Asfar P, Schortgen F, Boisramé-Helms J, et al. Hyperoxia and hypertonic saline in patients with septic shock (HYPERS2S): a two-by-two factorial, multicentre, randomised, clinical trial. Lancet Respir Med 2017;5:180-90.

8. Damiani E, Adrario E, Girardis M, et al. Arterial hyperoxia and mortality in critically ill patients: a systematic review and meta-analysis. Crit Care 2014;18:711.

9. Helmerhorst HJ, Roos-Blom MJ, van Westerloo DJ, et al. Association Between Arterial Hyperoxia and Outcome in Subsets of Critical Illness: A Systematic Review, MetaAnalysis, and Meta-Regression of Cohort Studies. Crit Care Med 2015;43:1508-19.

10. Nair GB, Niederman MS. Ventilator-associated pneumonia: present understanding and ongoing debates. Intensive Care Med 2015;41:34-48.

11. Cilloniz C, Martin-Loeches I, Garcia-Vidal C, et al. Microbial Etiology of Pneumonia: Epidemiology, Diagnosis and Resistance Patterns. Int J Mol Sci 2016;17. pii: E2120.

12. Turrens JF. Mitochondrial formation of reactive oxygen species. J Physiol 2003;552:335-44.

13. Kallet RH, Matthay MA. Hyperoxic acute lung injury. 
Respir Care 2013;58:123-41.

14. Vincent JL, De Backer D. Circulatory shock. N Engl J Med 2013;369:1726-34.

15. Magder S. Reactive oxygen species: toxic molecules or spark of life? Crit Care 2006;10:208.

16. Kuipers MT, van der Poll T, Schultz MJ, et al. Bench-tobedside review: Damage-associated molecular patterns in the onset of ventilator-induced lung injury. Crit Care 2011;15:235.

17. Penrod KE. Nature of pulmonary damage produced by high oxygen pressures. J Appl Physiol 1956;9:1-4.

18. Ohlsson WT. Study on Oxygen Toxicity at Atmospherie Pressure. Acta Med Scand 1947;190.

19. Stadie WC, Riggs BC, Haugaard N. OxygenPoisoning. Am J Med Sci 1944;207:84-114.

20. Helmerhorst HJF, Schouten LRA, Wagenaar GTM, et al. Hyperoxia provokes a time- and dose-dependent inflammatory response in mechanically ventilated mice, irrespective of tidal volumes. Intensive Care Med Exp 2017;5:27.

21. Sackner MA, Landa J, Hirsch J, et al. Pulmonary effects of oxygen breathing. A 6-hour study in normal men. Ann Intern Med 1975;82:40-3.

22. Huang YC, Caminiti SP, Fawcett TA, et al. Natural surfactant and hyperoxic lung injury in primates. I. Physiology and biochemistry. J Appl Physiol (1985) 1994;76:991-1001.

23. Dantzker DR, Wagner PD, West JB. Proceedings: Instability of poorly ventilated lung units during oxygen breathing. J Physiol 1974;242:72P.

24. Whiting J, Edriss H, Nugent K. Frequency and Etiology of Ventilator-Associated Events in the Medical Intensive Care Unit. Am J Med Sci 2015;350:453-7.

25. Edmark L, Kostova-Aherdan K, Enlund M, et al. Optimal oxygen concentration during induction of general anesthesia. Anesthesiology 2003;98:28-33.

26. Pelosi $\mathrm{P}$, Jaber $\mathrm{S}$. Noninvasive respiratory support in the perioperative period. Curr Opin Anaesthesiol 2010;23:233-8.

27. Kallet RH. Adjunct therapies during mechanical ventilation: airway clearance techniques, therapeutic aerosols, and gases. Respir Care 2013;58:1053-73.

28. Patel VS, Sitapara RA, Gore A, et al. High Mobility Group Box-1 mediates hyperoxia-induced impairment of Pseudomonas aeruginosa clearance and inflammatory lung injury in mice. Am J Respir Cell Mol Biol 2013;48:280-7.

29. O'Reilly PJ, Hickman-Davis JM, Davis IC, et al. Hyperoxia impairs antibacterial function of macrophages through effects on actin. Am J Respir Cell Mol Biol
2003;28:443-50.

30. Wang M, Gorasiya S, Antoine DJ, et al. The compromise of macrophage functions by hyperoxia is attenuated by ethacrynic acid via inhibition of $\mathrm{NF}-\kappa \mathrm{B}$-mediated release of high-mobility group box-1. Am J Respir Cell Mol Biol 2015;52:171-82.

31. Morrow DM, Entezari-Zaher T, Romashko J 3rd, et al. Antioxidants preserve macrophage phagocytosis of Pseudomonas aeruginosa during hyperoxia. Free Radic Biol Med 2007;42:1338-49.

32. Tateda K, Deng JC, Moore TA, et al. Hyperoxia mediates acute lung injury and increased lethality in murine Legionella pneumonia: the role of apoptosis. J Immunol 2003;170:4209-16.

33. Kikuchi Y, Tateda K, Fuse ET, et al. Hyperoxia exaggerates bacterial dissemination and lethality in Pseudomonas aeruginosa pneumonia. Pulm Pharmacol Ther 2009;22:333-9.

34. Raffin TA, Simon LM, Braun D, et al. Impairment of phagocytosis by moderate hyperoxia (40 to 60 per cent oxygen) in lung macrophages. Lab Invest 1980;42:622-6.

35. Nara C, Tateda K, Matsumoto T, et al. Legionella-induced acute lung injury in the setting of hyperoxia: protective role of tumour necrosis factor-alpha. J Med Microbiol 2004;53:727-33.

36. de Graaff AE, Dongelmans DA, Binnekade JM, et al. Clinicians' response to hyperoxia in ventilated patients in a Dutch ICU depends on the level of FiO2. Intensive Care Med 2011;37:46-51.

37. Smith JL. The pathological effects due to increase of oxygen tension in the air breathed. J Physiol 1899;24:19-35.

38. Clark JM, Lambertsen CJ. Pulmonary oxygen toxicity: a review. Pharmacol Rev 1971;23:37-133.

39. van Kaam AH, Lachmann RA, Herting E, et al. Reducing atelectasis attenuates bacterial growth and translocation in experimental pneumonia. Am J Respir Crit Care Med 2004;169:1046-53.

40. Forel JM, Voillet F, Pulina D, et al. Ventilator-associated pneumonia and ICU mortality in severe ARDS patients ventilated according to a lung-protective strategy. Crit Care 2012;16:R65.

41. Carvalho CR, de Paula Pinto Schettino G, Maranhão B, et al. Hyperoxia and lung disease. Curr Opin Pulm Med 1998;4:300-4.

42. Baleeiro CE, Wilcoxen SE, Morris SB, et al. Sublethal hyperoxia impairs pulmonary innate immunity. J Immunol 2003;171:955-63.

43. Gore A, Muralidhar M, Espey MG, et al. Hyperoxia 
sensing: from molecular mechanisms to significance in disease. J Immunotoxicol 2010;7:239-54.

44. Eastwood G, Bellomo R, Bailey M, et al. Arterial oxygen tension and mortality in mechanically ventilated patients. Intensive Care Med 2012;38:91-8.

45. Martin-Loeches I, Povoa P, Rodríguez A, et al. Incidence and prognosis of ventilator-associated tracheobronchitis (TAVeM): a multicentre, prospective, observational study. Lancet Respir Med 2015;3:859-68.

46. Jaffal K, Six S, Zerimech F, et al. Is hyperoxaemia a risk factor for ICU-acquired pneumonia? Lancet Respir Med 2017;5:e16.

47. Ego A, Preiser JC, Vincent JL. Impact of diagnostic criteria on the incidence of ventilator-associated pneumonia. Chest 2015;147:347-55.

48. Rachmale S, Li G, Wilson G, et al. Practice of excessive $\mathrm{F}(\mathrm{IO}(2))$ and effect on pulmonary outcomes in mechanically ventilated patients with acute lung injury. Respir Care 2012;57:1887-93.

49. Mehta A, Bhagat R. Preventing Ventilator-Associated Infections. Clin Chest Med 2016;37:683-92.

50. Six S, Jaffal K, Ledoux G, et al. Hyperoxemia as a risk factor for ventilator-associated pneumonia. Crit Care 2016;20:195.

51. Kallet RH, Branson RD. Should Oxygen Therapy Be Tightly Regulated to Minimize Hyperoxia in Critically Ill Patients? Respir Care 2016;61:801-17.

52. Helmerhorst HJ, Roos-Blom MJ, van Westerloo DJ, et al. Associations of arterial carbon dioxide and arterial oxygen concentrations with hospital mortality after resuscitation from cardiac arrest. Crit Care 2015;19:348.

53. Panwar R, Hardie M, Bellomo R, et al. Conservative versus Liberal Oxygenation Targets for Mechanically Ventilated Patients. A Pilot Multicenter Randomized Controlled Trial. Am J Respir Crit Care Med 2016;193:43-51.

54. Suzuki S, Eastwood GM, Glassford NJ, et al. Conservative oxygen therapy in mechanically ventilated patients: a pilot before-and-after trial. Crit Care Med 2014;42:1414-22.

55. Suzuki S, Eastwood GM, Goodwin MD, et al. Atelectasis and mechanical ventilation mode during conservative oxygen therapy: A before-and-after study. J Crit Care 2015;30:1232-7.

56. Helmerhorst HJ, Schultz MJ, van der Voort PH, et al. Effectiveness and Clinical Outcomes of a Two-Step Implementation of Conservative Oxygenation Targets in Critically Ill Patients: A Before and After Trial. Crit Care Med 2016;44:554-63.

57. Martin DS, Grocott MP. Oxygen therapy in critical illness: precise control of arterial oxygenation and permissive hypoxemia. Crit Care Med 2013;41:423-32.

58. He HW, Liu DW. Permissive hypoxemia/conservative oxygenation strategy: Dr. Jekyll or Mr. Hyde? J Thorac Dis 2016;8:748-50.

59. BOOST-II Australia and United Kingdom Collaborative Groups, Tarnow-Mordi W, Stenson B, et al. Outcomes of Two Trials of Oxygen-Saturation Targets in Preterm Infants. N Engl J Med 2016;374:749-60.

60. Claure N, D'Ugard C, Bancalari E. Automated adjustment of inspired oxygen in preterm infants with frequent fluctuations in oxygenation: a pilot clinical trial. J Pediatr 2009;155:640-5.e1-2.

61. Rice KL, Schmidt MF, Buan JS, et al. AccuO2 oximetrydriven oxygen-conserving device versus fixed-dose oxygen devices in stable COPD patients. Respir Care 2011;56:1901-5.

62. Saihi K, Richard JC, Gonin X, et al. Feasibility and reliability of an automated controller of inspired oxygen concentration during mechanical ventilation. Crit Care 2014;18:R35.

63. Arnal JM, Wysocki M, Novotni D, et al. Safety and efficacy of a fully closed-loop control ventilation (IntelliVent-ASV®) in sedated ICU patients with acute respiratory failure: a prospective randomized crossover study. Intensive Care Med 2012;38:781-7.

64. Lellouche F, Bouchard PA, Simard S, et al. Evaluation of fully automated ventilation: a randomized controlled study in post-cardiac surgery patients. Intensive Care Med 2013;39:463-71.

65. Arita Y, Kazzaz JA, Joseph A, et al. Antioxidants improve antibacterial function in hyperoxia-exposed macrophages. Free Radic Biol Med 2007;42:1517-23.

66. Arita Y, Joseph A, Koo HC, et al. Superoxide dismutase moderates basal and induced bacterial adherence and interleukin-8 expression in airway epithelial cells. Am J Physiol Lung Cell Mol Physiol 2004;287:L1199-206.

67. Patel VS, Sampat V, Espey MG, et al. Ascorbic Acid Attenuates Hyperoxia-Compromised Host Defense against Pulmonary Bacterial Infection. Am J Respir Cell Mol Biol 2016;5 5:511-20.

68. Saito K, Kimura S, Saga T, et al. Protective effect of procysteine on Acinetobacter pneumonia in hyperoxic conditions. J Antimicrob Chemother 2013;68:2305-10.

Cite this article as: Jaffal K, Six S, Zerimech F, Nseir S. Relationship between hyperoxemia and ventilator associated pneumonia. Ann Transl Med 2017;5(22):453. doi: 10.21037/ atm.2017.10.15 